\title{
Evaluation of Ultrasonographic fetal kidney length for Gestational age Detection in late second and third Trimesters
}

\section{Amal S. Zaghloul}

Fellow of Obstetrics \& Gynecology. Ultrasound Special Care Unit for the Fetus, Maternity Hospital Ain Shams University.

Corresponding author: Amal S. Zaghloul, Fellow of Obstetrics \& Gynecology. Ultrasound Special Care Unit for the Fetus, Maternity Hospital Ain Shams University Cairo, EGYPT

Received date: September 28, 2020; Accepted date: October 06, 2020; Published date: October 14, 2020

Citation: Amal S. Zaghloul (2020) Evaluation of ultrasonographic fetal kidney length for gestational age detection in late second and third trimesters. J Women Health Care Issues. J Women Health Care Issues, 3(4); Doi:10.31579/2642-9756/036

Copyright: (c) 2020 Amal S. Zaghloul, This is an open access article distributed under the Creative Commons Attribution License, which permits unrestricted use, distribution, and reproduction in any medium, provided the original work is properly cited.

\section{Abstract}

Accurate estimation of gestational age is necessary to obtain materials for different tests as well as to interpret the results of these tests.Unfortunately sometimes calculation of EDD based on LMP becomes very difficult when (a) The menstrual cycle is irregular; (b) Patient fails to remember LMP or reports inaccurately (c) Pregnancy occurs during lactational amenorrhoea \& (d) if patient have bleeding in early pregnancy. After 24 weeks the symphysio-fundal height in $\mathrm{cm}$. approximates to the number of weeks up to 36 weeks of gestation. But a number of factors influence the measurement including multiple gestation, IUGR, diabetic pregnancy, maternal size, variation in fetal lie \& engagement as well as inter \& intra observer measurement variation.Ultrasonic measurement of fetal biometry (CRL, BPD, FL) are considered to be reliable when they are performed in first \& early 2nd trimester ( $<24$ weeks).

In this study, we aimed to evaluate the accuracy of ultrasonographic fetal kidney length measurement as a new parameter for estimation of gestational age in late second and third trimester in correlation to other commenly used parameters as, BPD, FL, AC.

This study was conducted on 122 pregnant women attending antenatal care clinics of Obstetrics and Gynecology department Soliman Fakeeh Hospital, KSA. All were in the late second and third trimester (between 24-40 weeks) of gestation. Cases included in the study were divided into four gestational age groups with four weeks interval. The length of the fetal kidney was measured. The mean gestational age was calculated on the bases of biparietal diameter (BPD).femur length (FL) and abdominal circumference (AC) .The fetal kidney measurements were obtained by the same sonographer to avoid interobserver variation using (GE machine E8) and were compared with gestational age using statistical analysis

No statistically significant differences were found between the right and the left renal measurements in cases in which the two kidneys were imaged In this study, during the second and third trimester the mean kidney length showed gradual rate of increase. the mean kidney length was found to be $30.52 .1 \mathrm{~mm}$ at mean gestational age of 26weeks and became at the mean gestational age of 34 weeks, $40.4103 \mathrm{~mm}(:( \pm 1.98)$ and at mean gestational age of 38 week it measured44.41 $\mathrm{mm}(( \pm 2.1)$.

In addition, we found a positive correlation between kidney length and gestational age. We suggested regression Formula to calculate it.

\section{Conclusion:}

Throughout this study, we can conclude that Fetal kidney length could be used with accuracy in the late second and third trimester especially in women who are uncertain of date of LMP and are booked late for ANC.however its accuracy is decreased when we use it in late third trimester.Other ultrasonographic parameters used for estimation of the gestational age as BPD AC are less satisfactory, when compared with femur length and kidney length.

Keywords: fetal biparietale diameter; gynecology; pandemics; pregnancy

\section{Introduction:}

An accurate estimation of gestational age is considered a main determinant of maternity care quality as fetal growth assessment and to schedule the date of labor. Any fault in its estimation may lead to perinatal morbidity or even mortality [1].
On the other hand, development of new diagnostic ultrasound has created more possibilities for accurate assessment of pregnancy dating. In the first trimester gestational age (GA) can be estimated by ultrasonic 
measurement of crown rump length (CRL) as well as the diameter and the volume of gestational sac [2].

Other biometric indices like femur length (FL), fetal biparietal diameter (BPD), head circumference (HC), transcerebellar diameter (TCD), clavicle length (CL) and foot length are used for estimation of GA during different trimesters of pregnancy [3].

Fetal biometry measurements are considered accurate indices for estimation of GA in the early $2^{\text {nd }}$ trimester. However, as the age of fetus advances the biological diversity of Fetal size limits the accuracy of these parameters and makes an accurate dating in late $2^{\text {nd }}$ and $3^{\text {rd }}$ trimesters is difficult. So, new studies try to introduce more confident parameters as the association of kidney size in a normal fetus with GA [4].

In 1987 Goldstein and his colleagues used the fetal colonic echogenicity with transverse diameter of the colon to detect intestinal development which used as an indicator of gestational age [5].

Fetal kidneys in the 2nd and 3rd trimesters typically have the same configuration as in postnatal life and their appearance depends on the GA at which the study is conducted .Estimation of the length of the fetal kidney was found to be highly correlated with the gestational age, and so estimation of length of fetal kidney was advised for estimation of the fetal maturity(Ibrahim, 2017).

\section{Aim of the work}

The aim of this work is evaluation the accuracy of ultrasonographic fetal kidney length measurement as a new parameter for estimation of gestational age in late second and third trimester in correlation to other commonly used parameters as BPD, FL and AC.

\section{Subjects and Methods}

A total of 122 pregnant women attending the antenatal care clinic of Obstetrics and Gynecology department, Soliman Fakeeh Hospital, (KSA). Between January 2019 and February 2020 were studied cross sectionally from 24 weeks to 40 weeks gestational age. All have singleton fetus. Their LMP was well known and confirmed by initial ultrasonographic scan before 20 weeks.

All cases were subjected to the following: Full history taking, Routine general and obstetric examination and Routine antenatal care investigation. Ultrasound examination was done by (GE machine, E6) Ultrasound medical machine equipped with a multi frequency 5-7.5 MHZ abdominal probes.

Fetal kidney length (FKL) measurement was done and other fetal measurements BPD, FL, AC were obtained.

The studied cases were divided into four gestational age groups with 4 weeks interval divided as:

1- Group 1: gestational age from 24-28 weeks

2- Group 2: gestational age from 28 -32weeks

3- Group 3: gestational age from 32-36weeks

4- Group 4: gestational age from 36-40weeks

\section{Selection criteria:}

(1) Singleton pregnancy
(2) Gestational age between (24-40 weeks).

(3) Women sure of the date of their LMP.

The following cases were excluded from the study:

1. Fetuses having sonographic evidence of congenital fetal anomalies

2. Abnormal renal morphology.

3. Unclear renal or adrenal borders.

4. Oligohydramnios, polyhydramnios, PROM.

5. If there was marked discrepancy between the gestational age determined by fetal biometry and the last menstrual period (if the difference was greater than two weeks for gestational ages less than 30 weeks or if the difference was greater than 3 weeks for gestational ages equal 30 weeks or more).

6. High risk pregnancy

7. Preterm deliveries.

8. Fetal macrosomia.

Ultrasonographic examination of cases to assess the following parameters:

- Measurement of the biparietal diameter (BPD).

- Measurement of the femur length (FL).

- Measurement of the abdominal circumference (A.C)

- Measurement of the fetal kidney length (FKL). The same sonographer examined all cases to avoid interobserver variability.

A- Measurement of the biparietal Diameter (BPD):

This measurement was taken from transaxial sonograms of the fetal head at the level of the paired thalami and cavum septi pellucidi The BPD was measured from the outer edge of the cranium nearest the transducer to the inner edge of the cranium farthest from the transducer (outer to inner measurement) and perpendicular to the midline .

B- Measurement of the femur Length (FL)

The length of the diaphysis of the fetal femur was often used for gestational age prediction. The entire femur was imaged, and the thin bright reflection of the cartilaginous epiphysis should not be included in the measurement.

\section{C- Measurement of the abdominal circumference (AC):}

The fetal abdominal circumference was measured on transverse scan at the outer perimeter of fetal abdomen at the level of the fetal stomach and intrahepatic portion of the umbilical vein both the anteropostrior and the other transverse diameter were taken.

D - Measurement of the fetal kidney length (FKL):

Fetal kidney identification before 17 weeks may be very difficult for a routine sonographist. We choose 24 weeks for beginning of our study because identification of the kidneys is difficult at the beginning of the second trimester. The kidneys are not easily distinguished from the liver and bowel since the renal capsule cannot be identified at this stage. Conversely, at 24 weeks of gestation the renal capsule is highly echogenic.

The fetal kidneys were best identified in transverse plane (Fig I\&II) where they could be seen on either side of the fetal lumbar spine after determination of the fetal lie; the transducer was rotated to an axial plane and kept perpendicular to the fetal spine. 

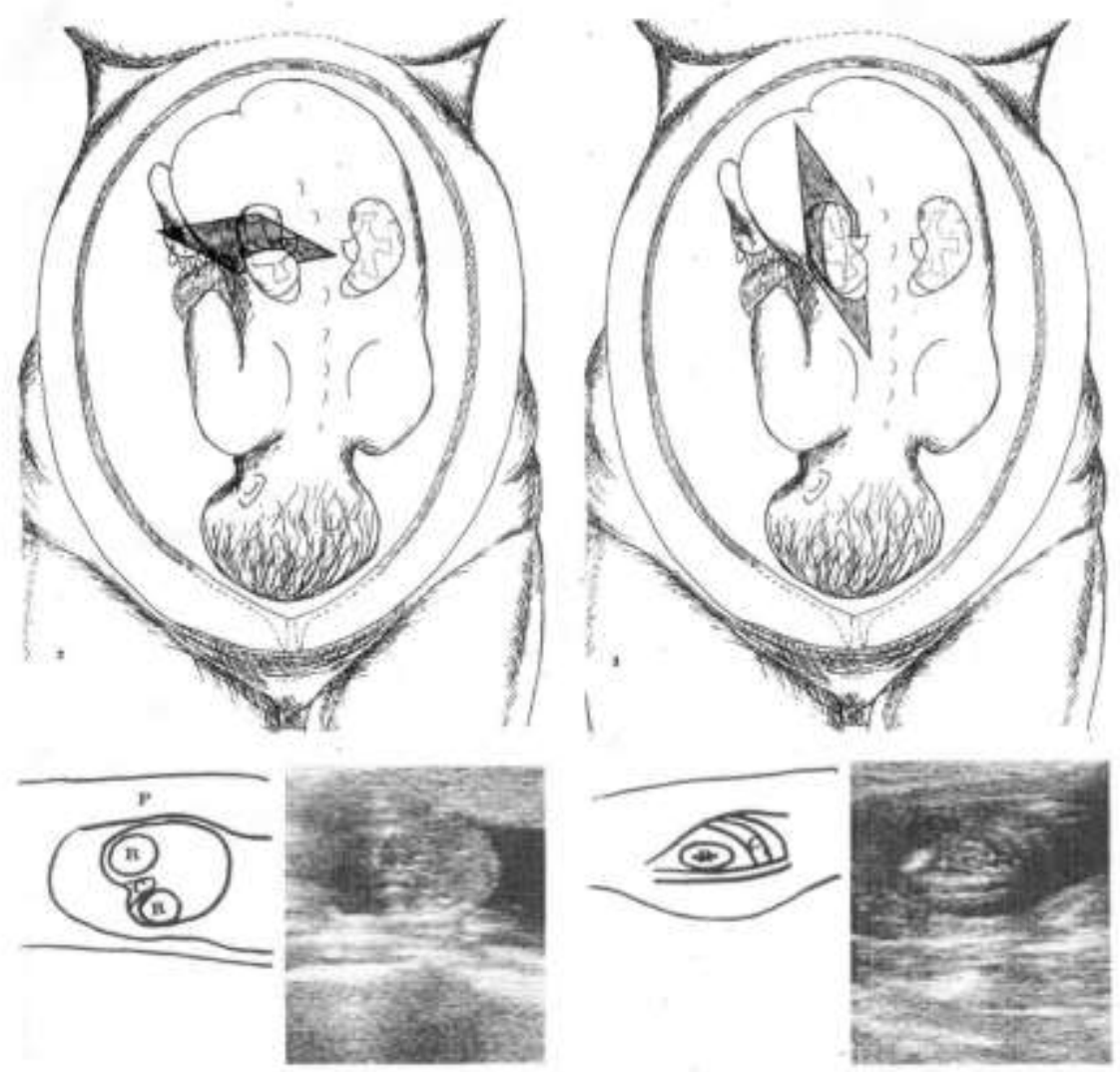

Figure 1: I- Identification of the fetal kidneys on transverse imaging (16th week of pregnancy) II- Longitudinal imaging of the fetal kidneys (16th week of pregnancy)

All the measurements were performed during fetal apnea. For the kidney length measurements, the fetus was scanned in the transverse plane until the kidneys were visualized just below the stomach. The probe was then rotated through $90^{\circ}$ to outline the longitudinal axis of the kidneys.

Where there were difficulties measuring both kidneys (due to the position of the fetus), the mother was allowed to wander outside the investigation room for 30-45 min and then return for repeat scanning. At the outset, failure to obtain measurements of kidneys at any stage led to automatic exclusion from the study, we did not find any differences between measurements from both kidneys. It was therefore no longer an exclusion criterion. Care was taken to exclude the adrenal glands in the measurements. Fetal biometric indices were measured blind to the kidney length measurements.

Location of major landmark. Such as the heart, liver, aorta, kidneys and urinary bladder helped in determination of the correct level of section. Coronal and sagittal scans could be obtained through the proper rotation of the transducer from this axial plane.

The long axis of the fetal kidney was obtained in a paraxial scan (fig 4) of the fetal abdomen at the level of the fetal lumbar spine. The superior and inferior poles of the kidney were marked and the longitudinal scans were obtained at sequential intervals until the maximum mid sagittal plane was determined. This represented the renal length. From the same long axis image of the fetal kidney.

Length of the kidney along its main axis. This parameter was measured on a longitudinal parasagittal cut of the fetal abdomen. Markers were placed on the image of the renal capsule with care being taken to exclude the adrenal gland and expose the upper pole of the kidney from the shadow of the lowermost ribs. Care was also taken to clearly distinguish the lower pole of the kidney from the gastrointestinal tract, especially the colon. The measured length of the kidney was checked on coronal imaging whenever possible. In order not to overestimate the length of the kidney, it is important to distinguish the upper pole of the kidney from the adrenal gland. In this respect, it should be borne in mind that unlike the kidney, the central part of the adrenal gland is not highly echogenicity. Furthermore, the investigator should seek to identify the continuity of the renal capsule in the region of the upper pole of the kidney. Top quality sonographs allow clear identification of the adrenal gland as a relatively large triangular structure lying over the superomedial part of the kidney. The cortex and medulla of the adrenal gland give a highly characteristic image which is denser than that of the kidney.

\section{Statistical Analysis}

The data were entered, checked and analyzed using Epi- Info version 6.02 and SPP for windows version 8.

\section{Results}

This cross-sectional observational study includes 122 pregnant females in four gestational age groups with 4 weeks interval divided as: 
Group 1: gestational age from 24-28 weeks

Group 2: gestational age from 28 -32weeks

Group 3: gestational age from 32-36weeks

Group 4: gestational age from 36-40weeks

Regarding the sonographic appearance of the fetal kidney, in the present work, we identified both fetal kidneys in 111 cases and it was difficult in 11 cases due to position of the fetus.Both kidneys were identified as an elliptical profile in longitudinal section and a circular profile in transverse section. There is no significant difference between right and left fetal kidney length. The results of this study are collected, Arranged, Tabulated, analyzed statistically and are presented in tables as follows : The mean age of cases was distributed as $28.19 \pm 4.78$ with minimum 17 and maximum 39, GA was distributed as $31.95 \pm 4.62$ with minimum 24 and maximum $40.34 .45 \%$ of studied cases was nullipara (P0) and $65.55 \%$ were multipara (P1,p2,p3and >p3). BMI was distributed as $26.85 \pm 3.98$ with minimum 18.4 and maximum 35 .About two third of studied cases were obese and overweight.The mean fetal kidney length at mean gestational age of 26weeks30.5mm $( \pm 2.1)$ ranging from $(27.10$ to $34.40 \mathrm{~mm})$ and at mean gestational age 30 weeks measured $36.2355 \mathrm{~mm}$ ( \pm o. 1.56728), ranging from (33 to $38.9 \mathrm{~mm}$ ) and at the mean gestational age of34 weeks, it measured 40.4103 $\mathrm{mm}(:( \pm 1.98537)$ ranging, from (35.10to $46.30 \mathrm{~mm})$.and at mean gestational age of 38 week it measured $44.41 \mathrm{~mm}(( \pm 2.1)$. There is highly significant correlation between GA and all parameters (BPD, FL, KL, and AC). There was significant difference among different GA category regard all parameters. There is Significant regression with suggested formula, and the most accurate parameters were the FL and kidney length $\left(r^{2}=0.965\right.$ and 0.905 respectively), while the least accurate was the BPD $\left(r^{2}=0.581\right)$. The highest correlation is with kidney length at 24-28 weak ( $\mathrm{r}=$ 0.992), but this correlation become week with advancement of GA especially kidney length in $36-40$ weak $(r=0.516)$.No significant difference between GA and GA estimated by each parameter $\mathrm{p}$ value $>0.05$ ).

\begin{tabular}{|c|c|c|c|}
\hline & & Age & GA \\
\hline & & $28.19 \pm 4.78$ & $31.95 \pm 4.62$ \\
\hline & nge) & $28.0(17-39)$ & $32.0(24-40)$ \\
\hline & & $\mathrm{N}$ & $\%$ \\
\hline Parity & P0 & 42 & 34.45 \\
\hline & $\mathrm{P} 1$ & 28 & 22.95 \\
\hline & $\mathrm{P} 2$ & 27 & 22.13 \\
\hline & P3 & 14 & 11.47 \\
\hline & $>\mathrm{p} 3$ & 11 & 9 \\
\hline & Total & 122 & 100 \\
\hline & & $\mathrm{N}$ & $\%$ \\
\hline & & 43 & 35.2 \\
\hline Ove & lobese & 79 & 64.8 \\
\hline & & 122 & 100.0 \\
\hline BMI & & Mean \pm SD & Median (Range) \\
\hline & & $26.85 \pm 3.98$ & $26.9(18.4-35.6)$ \\
\hline
\end{tabular}

Table 1: Age and GA, Parity, Obesity and BMI distribution among studied group (N=122)

\begin{tabular}{|c|c|c|}
\hline GA & N of cases & Mean kidney length \pm SD \\
\hline 24 & 4 & $27.67 \pm 0.43$ \\
\hline 25 & 8 & $28.47 \pm 0.78$ \\
\hline 26 & 6 & $30.45 \pm 0.77$ \\
\hline 27 & 8 & $31.60 \pm 0.90$ \\
\hline 28 & 8 & $33.06 \pm 0.99$ \\
\hline 29 & 9 & $34.62 \pm 0.91$ \\
\hline
\end{tabular}




\begin{tabular}{|c|c|c|}
\hline 30 & 8 & $35.81 \pm 1.17$ \\
\hline 31 & 6 & $37.01 \pm 0.38$ \\
\hline 32 & 8 & $37.90 \pm 0.92$ \\
\hline 33 & 9 & $38.59 \pm 1.51$ \\
\hline 34 & 8 & $40.21 \pm 0.69$ \\
\hline 35 & 6 & $41.12 \pm 0.44$ \\
\hline 36 & 6 & $42.61 \pm 2.24$ \\
\hline 37 & 10 & $42.72 \pm 2.54$ \\
\hline 38 & 8 & $44.56 \pm 2.49$ \\
\hline 39 & 6 & $44.45 \pm 3.69$ \\
\hline 40 & 4 & $45.62 \pm 0.47$ \\
\hline
\end{tabular}

Table 2: Changes in fetal kidney length with gestation Values $(\mathrm{mm})$ are mean \pm standard deviations.

\begin{tabular}{|c|c|c|c|c|c|c|}
\hline GA & & & BPD & FL & Kidney length & $\mathrm{AC}$ \\
\hline \multirow[t]{2}{*}{$24-28$} & \multirow[t]{2}{*}{ GA } & $\mathrm{R}$ & $0.921^{* * *}$ & $0.988^{* *}$ & $0.992^{* *}$ & $0.983^{* *}$ \\
\hline & & $\mathrm{P}$ & .000 & .000 & .000 & .000 \\
\hline \multirow[t]{2}{*}{$28-32$} & \multirow[t]{2}{*}{ GA } & $\mathrm{R}$ & $0.761^{* *}$ & $0.807^{* *}$ & $0.828^{* * *}$ & $0.820^{* * *}$ \\
\hline & & $\mathrm{P}$ & .000 & .000 & .000 & .000 \\
\hline \multirow[t]{2}{*}{$32-36$} & \multirow[t]{2}{*}{ GA } & $\mathrm{R}$ & $0.858^{* * *}$ & $0.900^{* *}$ & $0.747^{* *}$ & $0.810^{\text {*** }}$ \\
\hline & & $\mathrm{P}$ & .000 & .000 & .000 & .000 \\
\hline \multirow[t]{2}{*}{$36-40$} & \multirow[t]{2}{*}{ GA } & $\mathrm{R}$ & $0.835^{* *}$ & $\mathbf{0 . 8 5 0}^{* *}$ & $0.516^{* * *}$ & $0.837^{* * *}$ \\
\hline & & $\mathrm{P}$ & .000 & .000 & .005 & .000 \\
\hline
\end{tabular}

Table 3: Correlations between GA and estimated GA by each parameter (BPD, FL, Kidney length and AC) at different GA categories.

\begin{tabular}{|c|c|c|c|c|c|c|c|c|}
\hline & & $\mathrm{N}$ & Mean & Std. Deviation & Minimum & Maximum & $\mathrm{F}$ & $\mathrm{P}$ \\
\hline \multirow[t]{4}{*}{ BPD } & $24-28$ & 30 & 65.2145 & 5.42354 & 52.80 & 75.40 & \multirow[t]{4}{*}{247.554} & \multirow[t]{4}{*}{$0.00 * *$} \\
\hline & $28-32$ & 31 & 76.8974 & 3.3124 & 71.60 & 85.60 & & \\
\hline & $32-36$ & 30 & 85.811 & 2.64122 & 81.30 & 90.60 & & \\
\hline & $36-40$ & 31 & 94.5112 & 5.54211 & 86.00 & 110.00 & & \\
\hline \multirow[t]{4}{*}{ FL } & $24-28$ & 30 & 48.5541 & 4.45838 & 39.50 & 56.10 & \multirow[t]{4}{*}{331.168} & \multirow[t]{4}{*}{$\mathbf{0 . 0 0} * *$} \\
\hline & $28-32$ & 31 & 59.7108 & 3.32145 & 53.40 & 65.10 & & \\
\hline & $32-36$ & 30 & 68.1586 & 2.43582 & 64.20 & 73.20 & & \\
\hline & $36-40$ & 31 & 74.9874 & 3.25478 & 69.20 & 83.00 & & \\
\hline \multirow{3}{*}{$\begin{array}{l}\text { Kidney } \\
\text { length }\end{array}$} & $24-28$ & 30 & 30.5471 & 2.11492 & 27.10 & 34.40 & \multirow[t]{3}{*}{221.154} & \multirow[t]{3}{*}{$0.00 * * *$} \\
\hline & $28-32$ & 31 & 36.2365 & 1.56841 & 33.00 & 38.90 & & \\
\hline & $32-36$ & 30 & 40.4103 & 1.98537 & 35.10 & 46.30 & & \\
\hline
\end{tabular}




\begin{tabular}{|c|c|c|c|c|c|c|c|c|}
\hline & $36-40$ & 31 & 44.4124 & 3.12145 & 38.00 & 48.00 & & \\
\hline \multirow[t]{4}{*}{$\mathrm{AC}$} & $24-28$ & 30 & 216.612 & 19.16363 & 184.00 & 265.00 & \multirow[t]{4}{*}{351.812} & \multirow[t]{4}{*}{$\mathbf{0 . 0 0} * *$} \\
\hline & $28-32$ & 31 & 264.041 & 13.91314 & 237.00 & 286.30 & & \\
\hline & $32-36$ & 30 & 302.362 & 11.70784 & 286.00 & 333.00 & & \\
\hline & $36-40$ & 31 & 338.212 & 15.51429 & 316.00 & 380.00 & & \\
\hline
\end{tabular}

Table 4: The relationship between kidney length (KL), biparietal diameter (BPD), femur length (FL) and, abdominal circumference (AC) and gestational age (weeks).

\begin{tabular}{|l|l|c|c|c|c|c|}
\hline \multicolumn{2}{|l|}{ Model } & R & $r^{2}$ & F & P & Formula of regression \\
\hline \multirow{2}{*}{ BPD } & 0.762 & 0.581 & 12.84 & $0.00 * *$ & GA=10.3+(BPD*0.27) \\
\cline { 2 - 6 } & FL & 0.982 & 0.965 & $\mathbf{5 7 . 6 9 0}$ & $\mathbf{0 . 0 0} * *$ & GA=51+(FL*0.43) \\
\cline { 2 - 6 } & Kidney length & $\mathbf{0 . 9 5 1}$ & $\mathbf{0 . 9 0 5}$ & $\mathbf{3 3 . 2 9 0}$ & $\mathbf{0 . 0 0} * *$ & GA=0.93+(Kidney length*0.83) \\
\cline { 2 - 6 } & AC & $\mathbf{0 . 9 0 0}$ & $\mathbf{0 . 8 1 1}$ & $\mathbf{2 2 . 0 8 7}$ & $\mathbf{0 . 0 0} * *$ & GA=10.4+(AC*0.078) \\
\hline
\end{tabular}

Table 5: Linear regression equations defining the relationship between gestational age and the various parameters used for gestational age estimation in the studied groups.

\begin{tabular}{|c|c|c|c|c|}
\hline & Mean & Std. Deviation & Paired $\mathbf{t}$ & $\mathbf{P}$ \\
\hline GA & 31.9508 & 4.62629 & \multirow[t]{2}{*}{0.710} & \multirow[t]{2}{*}{0.479} \\
\hline Estimated GA BY BPD & 31.8433 & 3.19139 & & \\
\hline GA & 31.9508 & 4.62629 & \multirow[t]{2}{*}{1.812} & \multirow[t]{2}{*}{0.072} \\
\hline Estimated GA by FL & 31.8083 & 4.55390 & & \\
\hline GA & 31.9508 & 4.62629 & \multirow[t]{2}{*}{-0.962} & \multirow[t]{2}{*}{0.338} \\
\hline Estimated GA by Kidney length & 32.0652 & 4.67943 & & \\
\hline GA & 31.9508 & 4.62629 & \multirow[t]{2}{*}{-0.498} & \multirow[t]{2}{*}{0.620} \\
\hline Estimated GA by AC & 32.0022 & 3.75905 & & \\
\hline
\end{tabular}

Table 6: Comparison of estimated GA by each parameter (BPD, FL, Kidney length and AC) with GA among studied groups.

\section{Discussion}

Determination of an accurate GA is very essential and mandatory in prenatal medicine .Estimation of an accurate GA and assessment of the fetal maturity is so crucial in a lot of clinical cases ,as cases of severe preeclampsia, chronic hypertension ,diabetic pregnancies ,antepartum hemorrhage, $\mathrm{RH}$ isoimmunization ,post maturity and so on .Induction of labour in such cases Markedly affected by the estimated GA . Failure in estimating GA accurately can result in unnecessary induction, dysfunctional labor, operative delivery, iatrogenic prematurity or postmaturity [6].

Ultrasonographic fetal biometry is the most widespread method used to establish GA. Various sonographic biometric parameters commonly used are Crown Lump Length (CRL), Biparietal diameter (BPD), Head circumference (HC), Abdominal circumference (AC) and Femur length (FL). CRL measurements accurately predict GA to within \pm 5-7 days but 
can be employed only in cases who present in 1st trimester [7].

In early 2nd trimester BPD, FL, $\mathrm{HC}$ and $\mathrm{AC}$ can predict GA with fair accuracy ( \pm 10 -11days, \pm 10 - 20 days, \pm 10 - 14 days and \pm 10 -14 days respectively). These parameters might be inaccurate in late pregnancy, especially when a pregnant woman cannot recall her LMP. Furthermore, there is a substantial evidence that the standard derivation for these indices are widen as pregnancy progresses and this will be even worse if the head is too low or an obvious plane cannot be obtained, which together will mislead the measurement of BPD and $\mathrm{H}$ [6].

Therefore, accurate estimation of GA in late 2nd and 3rd trimester still remains a problem. There is no single fetal measurement used for accurate estimation of gestational age in $3^{\text {rd }}$ trimester [8].

Therefore, many researches have been conducted to determine a precise estimation of GA using ultrasonic measurements throughout the second and the third trimester. Various non-traditional sonographic parameters for estimating GA are being studied like transverse cerebellar diameter, fetal foot length, epiphyseal ossification centers, amniotic fluid volume and placental grading.Ozat and his colleagues suggested that fetal sacral length can be used in dating labor due to the significant correlation between GA and sacral length they found [9].

Sherer and his colleagues used fetal hard palate width as an indicator of GA between 15- and 41-weeks' gestation. But the assessment of these measurements needs advanced ultrasonic skills. Therefore, we need other parameters that can give an accurate GA and can be measured easily [10]. Our study was conducted to evaluate the accuracy of fetal kidney length as a parameter of fetal gestational age measurement. 122 pregnant women in the second and third trimester with gestational ages ranging from 2440 weeks were studied cross sectionally to get ultrasound measurement of fetal kidney length.

In current study, the age range of participants was 17-39 years, with a mean age $28.19 \pm 4.78$ years.

From studied cases $34.45 \%$ were nulliparous and $65.55 \%$ were multipara. The BMI range of participants was (18.4-35.6), with a mean BMI $26.85 \pm 3.98$. About two third of studied cases were obese and overweight. In the present work, we observed statistically non-significant differences in fetal kidney length between the right and left kidneys in cases in which the two kidneys were imaged. Similar findings were reported by [11].

Brennan and his colleagues conducted systematic review to determine the role of ultrasound imaging in evaluating fetal kidney growth and stated that overall the evidence strongly supported no significant difference between right and left kidney size (17of the 18 included studies) [12]. So, we used mean kidney length for final statistical analysis.

Findings in the current study revealed that, the mean fetal kidney length at the mean gestational age of 26 weeks was $30.5 \mathrm{~mm}( \pm 2.1)$ ranging from (27.10 to $34.40 \mathrm{~mm})$ and at mean gestational age 30 weeks measured $36.2355 \mathrm{~mm}$ ( \pm o. 1.56728), ranging from ( 33 to $38.9 \mathrm{~mm}$ ) and at the mean gestational age of34 weeks, it measured $40.4103 \mathrm{~mm}(:( \pm 1.98537)$ ranging, from (35.10to $46.30 \mathrm{~mm}$ ).and at mean gestational age of 38 week it measured $44.41 \mathrm{~mm}(( \pm 2.1)$.

That is consistent with Chitty and Altman who found that mean kidney length at $26 \mathrm{w}, 30 \mathrm{w}, 34 \mathrm{w}$ and $38 \mathrm{w}$ was $30.3 \pm 0.12$, $36.0 \pm 0.12, \quad 40.3 \pm 0.12$ and $43.2 \pm 0.12$ respectively [13], Ahmadi and his colleagues found that mean kidney length at 26w,30w,34w and 38 was $29.38,35.23,39.7,42.45$ respectively [11].

But in contrast to our study, some studies recorded that mean kidney length at different GA were lower than in our study found [14].

A number of reasons could explain these differences. These include the number of operators (multiple vs. two skilled operators), type of study (cross-sectional vs. longitudinal), estimation of gestational age (rounded vs. exact), quality of ultrasound machine characteristics of subjects (only uncomplicated pregnancies vs. all pregnancies) and observer bias (nonblind vs. blind study).Improvement in sonographic technology may be the key factor resulting in our larger measurement as compared with earlier studies.

In the present study, all sonographic measurement was performed by single skilled sonologist. The mean BPD, FL, and AC measurements at various gestations observed in our study were similar to measurements obtained by [15].

There was highly significant correlation between them and GA and the highest significant correlation was with FL $(r=0.982)$ followed by fetal kidney length $(r=0.980)$, however this correlation became week with advancement of GA especially kidney length in 36-40 weak $(r=0.516)$. Also our study showed that there was linear regression equations defining the relationship between gestational age and the various parameters used for gestational age estimation in the studied groups. There is Significant regression with suggested formula, and the most accurate parameters were the FL and kidney length ( $\mathrm{r} 2=0.965$ and 0.905 respectively), while the least accurate was the BPD $(\mathrm{r} 2=0.581)$.

These finding are consistant with that of Konje and his colleagues who stated that Kidney length and femoral length were most accurate single parameters for predicting gestational age [16].

In Yusuf and his colleagues study there was significant correlation 
J Women Health Care Issues

between kidney length, BPD, FL and AC and GA and concluded that any one of the parameters can be used to determine gestational age [8].

Also Kaul and his colleague found strong correlation between fetal kidney length and gestational age (correlation coefficient $r=0.958$ ).so fetal kidney length was the most accurate single parameter for estimation of gestational age closely followed by FL.Abdominal circumference was the most inaccurate single parameter for estimation of gestational age [6]. The difference of mean fetal kidney length and other parameters in obese patients reported in the present study could be explained by that a thicker maternal abdominal wall is associated with reduced feasibility of completing an ultrasonography examination in a pregnant patient who is obese, and with poor image quality. The absorption of ultrasonography waves by subcutaneous fat makes ultrasonography more difficult and may result in poor scans and prevent proper measurement of both kidneys.

\section{Conclusion}

Throughout this study, we can conclude that

- Fetal kidney length could be used with accuracy in the late second and third trimester especially in women who are uncertain of date of LMP and are booked late for ANC.however its accuracy is decreased when we use it in late third trimester.

- In comparison with other ultrasonographic biometry methods, Femur length (FL) is the most sensitive for estimation of the gestational age in late second and third trimesters and it should be our first choice in such issue

- Other ultrasonographic parameters used for estimation of the gestational age as BPD, AC are less satisfactory, when compared with femur length and kidney length

\section{References:}

1. NGOOD, P. B., ARMSTRONG, E. M., ASHTON, D., BURSTIN, H., CORRY, M. P., DELBANCO, S. F., FILDES, B., FOX, D. M., GLUCK, P. A. \& GULlO, S. L. 2010. Blueprint for action: Steps toward a high-quality, high-value maternity care system. Women's Health Issues, 20, S18-S49.

2. BISSET, R. 2013. Differential Diagnosis in Obstetrics and Gynecologic Ultrasound-E-Book, Elsevier Health Sciences.

3. LIMA, J., MIYAGUE, A., NASTRI, C. \& MARTINS, W. 2012. Biometry and fetal weight estimation by two-dimensional and three-dimensional ultrasonography: an intraobserver and interobserver reliability and agreement study. Ultrasound in Obstetrics \& Gynecology, 40, 186-193.
Copy rights@Amal S. Zaghloul,

4. IBRAHIM, R. A. E. E. 2017. Estimation of Gestation Age by Fetus kidney length Using Ultrasonography. Sudan University of Science and Technology.

5. CONWAY, D. L., HANSEN, N. I., DUDLEY, D. J., PARKER, C. B., REDDY, U. M., SILVER, R. M., BUKOWSKI, R., PINAR, H., STOLL, B. J. \& VARNER, M. W. 2013. An algorithm for the estimation of gestational age at the time of fetal death. Paediatric and perinatal epidemiology, 27, 145-157.

6. KAUL, I., MENIA, V., ANAND, A. K. \& GUPTA, R. 2012. Role of Fetal Kidney Length in Estimation of Gestational Age. JK science, 14.

7. SRIMATHI, J., SUJATHA, K., SRIPREETHIKA, R. \& PADMANABAN, M. S. 2018. fetal kidney length: a new parameter for determination of gestational age in 3rd trimester. paripex-indian journal of research, 6 .

9. YUSUF, N., MOSLEM, F. \& HAQUE, J. A. 2007. Fetal kidney length: can be a new parameter for determination of gestational age in 3rd trimester. TAJ: Journal of Teachers Association, 20, $147-150$

10. OZAT, M., KANAT-PEKTAS, M., GUNGOR, T., GURLEK, B. \& CAGLAR, M. 2011. The significance of fetal sacral length in the ultrasonographic assessment of gestational age. Archives of gynecology and obstetrics, 283, 999-1004. SHERER, D. 2000. Is fetal hydronephrosis overdiagnosed? Ultrasound in Obstetrics \& Gynecology, 16, 601-606.

11. SHERER, D., SOKOLOVSKI, M., SANTOSO, P., DALLOUL, M. \& ABULAFIA, O. 2004. Nomograms of sonographic measurements throughout gestation of the fetal hard palate width, length and area. Ultrasound in Obstetrics and Gynecology: The Official Journal of the International Society of Ultrasound in Obstetrics and Gynecology, 24, 35-41.

12. AHMADI, F., TAQI DIZAJ, A., AKHBARI, F., HOHREH IRANI, S. \& HOLAMREZA KHALILI, G. 2015. Fetal kidney measurement in 26-39 weeks gestation in normal fetuses of iranian pregnant women. J Preg Child Health, 2, 2.

13. BRENNAN, S., WATSON, D., RUDD, D., SCHNEIDER, M. \& KANDASAMY, Y. 2017. Evaluation of fetal kidney growth using ultrasound: a systematic review. European journal of radiology, 96, 55-64.

14. CHITTY, L. S. \& ALTMAN, D. G. 2003. Charts of fetal size: kidney and renal pelvis measurements. Prenatal Diagnosis: 
Published in Affiliation with the International Society for Prenatal Diagnosis, 23, 891-897.

15. KANSARIA, J. \& PARULEKAR, S. 2009. Nomogram for fetal kidney length. Bombay Hospital Journal, 51, 155-162.

16. El FATTAH, A. T. A., SHABAN, H. S. \& YOUNIS, E. A. A. 2018. Comparison between Trans-cerebellar Diameter, Biparietal Diameter and Femur Length for Gestational Age
Measurement Accuracy in Third Trimester of Pregnancy. Egyptian Journal of Hospital Medicine, 73.

17. KONJE, J., ABRAMS, K., BELL, S. \& TAYLOR, D. 2002. Determination of gestational age after the 24th week of gestation from fetal kidney length measurements. Ultrasound in Obstetrics and Gynecology, 19, 592-559 (c) (†)

This work is licensed under Creative Commons Attribution 4.0 License

To Submit Your Article Click Here: Submit Article

DOI:10.31579/2642-9756/036

Ready to submit your research? Choose Auctores and benefit from:
rast, convenient online submission
raporous peer review by experienced research in your field
authors retain copyrights
immediate, unrestricted online access
At Auctores, research is always in progress.
Learn more https://www.auctoresonline.org/journals/women-health-care-
and-issues

